\title{
Literature Review on Chinese School Education Environment
}

\author{
Feng Ting \\ School of Teacher Education, Jiangsu University, Zhenjiang 212013, China \\ 18851401816@163.com
}

Keywords: educational environment; school education environment; function; problem; measure

\begin{abstract}
This paper systematically reviews and summarizes the educational environment of the school from two aspects: the definition of the concept and the domestic situation of the school education environment. The situation of school education includes the function of school education environment, the problems existing in the current school education environment and the measures to create good educational environment.
\end{abstract}

\section{Introduction}

With the progress of social civilization and the request of the high quality talents is more and more urgent, the development of high-quality talents can not be separated from a good school education environment. As an old saying goes: When one is surrounded by the virtuous he will become upright himself. All that illustrates the importance of environment education, and school is one of the most important places to educate. Ignoring the construction of school education environment, the goal of education is impossible to achieve. Therefore, we must pay attention to the school education environment and the shaping of the school education environment.

\section{The concept of definition}

\subsection{The educational environment}

Gu Mingyuan, an editor of "Education Dictionary", In this book, the concept of the educational environment is interpreted as to nurture people and consciously create the situation.

Dwight, an editor of the "Western Education Dictionary", the interpretation of educational environment is children can perceive or be affected by things, events and people.

Cheng Hongyan, in the "educational environment of the school", thinks that the educational environment refers to something affects their growth from the perspective of students. But she emphasizes the effects of specific people and things. Such an educational environment view takes into account the differences in the educational situation, believing that, even under the same physical conditions, they are also differences.

The author believes that Tian Hua whose understanding of the educational environment is more comprehensive in the "environmental education, educational environment and personality training" He believes that the educational environment, including macro-educational environment and micro-educational environment. The macro-educational environment refers to the surroundings associated with the center of education. Because education is a kind of social practice to train people, the center of education is "human". Therefore, the macro-educational environment refers to all the external world which directly or indirectly affects the survival and development of human beings, including natural environment, society and community environment. Micro-educational environment is to nurture people and consciously create the environment. It includes family education environment, school education environment and narrow social education environment. Because it has a certain purpose, it is different from the natural environment of education in the macro-educational environment. It is also different from the economic, political, technological, cultural and demographic environments in the social educational environment. 


\subsection{The school education environment}

"School education environment," the concept of the current understanding of it is not consistent. Here are some of the views of scholars.

Zhong Xuhuai in the "sword set up a good school education environment" thinks that the school education environment should include the natural environment and cultural environment. The so-called natural environment contains the school buildings, venues and facilities, interior layout, and campus greening, purification, landscaping and so on. The so-called cultural environment, refers to the school tradition, school spirit, moral style and interpersonal relationships.

Liu Yuhai in the "Analysis of University Education Environment" believes that the school education environment is take the university education as the main body, the object factors on school education and the implementation of the influence on the formulation of the surrounding university education "education" and "education plan". These objects are the objective existence of the relative school education, which has an influence on the school education.

The author is more inclined to the views of Peng Zuolu in "On the" school education environment "elements of several issues" .In this article he mentioned that from the philosophical point of view, the connotation of the term"school education environment", first of all, means that it is the external objective condition of the subject of "school education" in its existence, self-movement and development, and therefore it belongs to the object of "school education". In this sense there is a strict distinction between the relative existence of the status.The meaning of the so-called "school education environment" , in general, it refers to the main body of teaching at all levels of various types of schools in the process of teaching activities impose on the external conditions of those spiritual, material, natural, social.

\section{The domestic situation of the school education environment}

Through the reading of relevant literature and the analysis of the collected data, the author draws out the following three aspects of the research on the school education environment.

\subsection{The function of the school education environment}

Feng Xiangdong, In the "on the construction of the educational environment of colleges and universities", summarizes the function of school's educational environment as three aspects: First, to provide material basis for education activities of cultivating talents; Second, as the social environment which could influence students. Through the enlightenment and influence, it becomes the ideological, behavior norms; Third, to meet the needs of the operation of various teaching mechanisms. The educational mechanism refers to the internal relations of the educational process, including the ways and principles of these connections. The normal operation of the educational mechanism needs to have the corresponding environment.

Wang Wei-tao, Wang Jing-tao, in the "Analysis and Innovative Construction of Educational Environment in Higher Education Institutions", analyzes the functions of the educational environment in colleges and universities as follows: first, intelligent training is knowledge impartment, intelligent development and capacity enhancement.

From the above I can draw the conclusion that the importance of the school education environment mainly reflects on the promotion of moral, intellectual, psychological and other aspects.

\subsection{The current problems of the school education environment in China}

Through reading the relevant literature and analyzing the collected data, the author points out that the existing problems of the school education environment can be explained from the following two aspects.

\subsubsection{The school education in the hard environment problems}

Huang Liping and Chen Teshui pointed out,in the "disharmonious factors and optimization of the ideological and political education environment in colleges and universities" ,that since the 
expansion of higher education began in 1999, higher education gradually transformed from elite education to mass education, some colleges and universities can not adapt to changing environment . The negative effects on the hardware facilities, faculty and other aspects is growing.

\subsubsection{School education soft environment problems}

\subsubsection{Educational philosophy}

Xiang Hua, in the "status of school education environment," shows the primary and secondary education has not yet shrouded in the shadow of examination-oriented education, test scores are still important. A number of people only pursuit the enrollment rate.

\subsubsection{Style of study, school spirit}

Some schools only focus on the subject curriculum, ignoring the subtle influence of implicit curriculum on students' knowledge, feelings, beliefs, will, behavior and values, and other aspects.

Style of study, school spirit is also have a great influence on students, if students lack of the good style of study and school spirit, they will do not learn actively.

\subsubsection{The relationship between teachers and students}

Xiang Hua, in the "current situation of school education environment," mentions that the relationship between teachers and students in the primary and secondary school are not optimistic, only a small number of students and teachers are very happy to get along. The main reason is that teachers are still evaluating students by academic achievement, they also take different attitudes towards different students.

\section{The measures to create a good school education environment}

The author summarizes the existing problems in the school education environment from the two aspects, the measures of creating corresponding good educational environment are explained later.

\subsection{The hard environment of school education}

Li Biliang, in the "optimize the school environment to create a good educational atmosphere" mentions that the construction of a hard environment should be purified.

Qu Xiaolin, in the "university education environment and innovation ability" thinks that the innovation of material atmosphere embodied in the strengthening of hardware construction, from books, accommodation, restaurants, teaching, laboratory equipment, cultural and sports facilities, should become better . Library should prepare a large number of the various disciplines of the latest books and journals, reflecting the latest developments in various fields. Through reading, students can keep abreast of the latest technological development.

\subsection{Soft environment of school education,}

\subsubsection{Update the educational idea}

Fu Yunfeng, in the "create a modern school education environment to establish a comprehensive quality education base," writes that in the face of the opportunities and challenges of modern education, we must first update the concept of education, to create a good educational environment.

\subsubsection{To create a good school spirit and style of study}

Li Biliang, in the "optimizing the school environment to create a good educational atmosphere," points out that the construction of the school soft environment shuould create a good school spirit, style of study.

Xiang Hua, in the "Analysis of the current situation of school education environment," mentions that we should pay attention to the construction of campus culture and the development of social-led cultural convergence through radio, television, newspapers and other media. In the construction of the cultural environment of the class, we should attach the importance to the impact 
of spiritual and material cultural factors, especially with more flexible collective activities, so that the individual in the group could accept the class atmosphere of the edification.

\subsubsection{To create a new type of teacher-student relationship}

Wang Kongxin,"Constructing a Harmonious Teacher - student Relationship and Creating a Harmonious Educational Environment" thinks that teacher - student relationships include ethical relations and emotion relationship. Teacher-student relationship should be equal in personality, should be democratic and harmony in interactive activities.

Chen Jin,in the "establishment of the demand for education environment", mentions we should change the role of teachers. Traditional education makes educators always stands in the grant-type status, and students in the receiving position. To change this situation, you must set up the character exchange. Educators should play a role of director.

But here, the author thinks that practice of the establishment of a good teacher-student relationship is difficult, however, it should carry out based on different age groups. For example, for primary school students, considering of their age,we should pay attention to guidance, but also notice the appropriate authority. In general, according to the age and the specific circumstances of the class,we should adjust the teacher-student relationship.

In summary, the author believes that only combine the school hard environment with soft environment, it could have a positive impact on students.

\section{Conclusion}

In summary, a good school education environment is an invisible force of infection, silent action command, which plays a subtle influence on students. A good school education environment can make members often happy and promote the good development of each member psychologically.

Therefore, for the students, to create a harmonious, relaxed and pleasant learning environment in the near future is conducive to the development of students' mental health, in the long run, its impact on each student's personality is lifelong. The school should create a human development-oriented education environment, so that the concept of quality education could affect the daily education and teaching process.

\section{References}

[1] Gu Mingyuan. The first volume of the education dictionary [M] Shanghai shanghai education press, 1990.

[2] De Langtry Editor-in-Chief. Western Education Dictionary [M]. Shanghai: Shanghai Translation Publishing

[3] WANG Kong-xin. Constructing a Harmonious Teacher-Student Relationship and Creating a Harmonious Education Environment [J]. Chengcai Zhilu, 2008(2):11-12.

[4] Fu Yunfeng. Creating a Modern School Education Environment Establishing a Comprehensive Quality Education Base [J]. Journal of Zhejiang Wanli University, 1998(2): 23-24+22.

[5] Tian Hua. Environmental Education, Educational Environment and Personality Cultivation [J]. Heilongjiang Science and Technology Information, 2008(35): 257-257.

[6] Wang Yanxin. Interdisciplinary Education: The Only Way to Establish First-class Undergraduate Teaching in Chinese Universities__ Taking Environmental Undergraduate Teaching as an Example [J]. China Higher Education Research, 2016(6): 17-24.

[7] Zhang Huachun, Zhu Hui. Highlighting the Function of Cultural Education: Reflections on the Design of University Campus Environment [J]. University Education Science, 2012, 5(5): 17-20.

[8] Zhong Xuwei. Creating a Good School Education Environment [J]. Education Guide, 1991(10): 24-27. 
[9] CAI Jiyun, YANG Zhanling, LIU Yuhai. Research on Physical Education Teaching Model in Colleges and Universities in China [J]. Consumer Guide, 2012(7): 176-176.

[10] Xiang Hua. Analysis of the Current Situation of School Education Environment [J]. Journal of Xi'an University of Arts and Science (Natural Science Edition), 2004, 19(4): 34-36.

[11] Lü Ming, Ji Anxian, Liu Wenjing. A Study on the Educational Environment of Contemporary Chinese Universities [J]. Journal of Ocean University of China (Social Science Edition), 2008(2): 44-47.

[12] Feng Xiangdong. On the Construction of Higher Education Environment [J]. Higher Education Research, 1986(4):23-27.

[13] Wang Wei, Wang Jingtao. Analysis and Innovation Construction of University Education Environment [J]. Journal of Shenyang University (Social Science Edition), 2007, 9(2): 45-47.

[14] Huang Liping, Chen Teshui. Disharmonious Factors and Optimization of Current Ideological and Political Education Environment in Colleges and Universities [J]. Journal of Hunan First Teachers College, 2008, 8(3): 61-63.

[15] Li Yuliang. Optimizing the School Education Environment and Creating a Good Education Environment [J]. Chinese Education Journal, 2002(6): 32-33.

[16] Qu Xiaolin. Cultivation of University Education Environment and Innovation Ability [J]. Higher Education and Academic Research, 2008(8).

[17] Sang Zhijian. Alienation and Governance of Modern School Education Time [J]. Modern Education Management, 2016(10):40-43. 